\title{
El análisis de la muerte según Bernhard Welte Consideraciones fenomenológicas
}

\author{
CÉSAR LAMBERT ORTÍZ \\ Universidad Católica del Maule (Chile) \\ clambert@ucm.cl
}

\begin{abstract}
Resumen
El texto trata del acceso fenomenológico a la muerte. El punto de partida de la reflexión está constituido por la descripción de la muerte que hace Bernhard Welte como un momento en el cual el ser humano alcanza su totalidad. Así, cuando se considera a una persona fallecida, experimentamos una transfiguración en su imagen, de tal modo que el momento de la muerte puede ser calificado como un instante numinoso y sacro. Si se compara esta descripción con el análisis que Martin Heidegger ofrece en Ser y tiempo, constatamos diferentes accesos. Heidegger intenta mostrar que la muerte no puede ser definida por la vía del trato con la muerte de otra persona, sino solo describiendo la relación individual con la propia muerte. Finalmente, el texto discute el concepto que Eugen Fink ofrece de la muerte, el cual tiene dos aspectos: la dimensión solitaria (la propia muerte) y su dimensión social (la muerte de los otros). Ambas dimensiones se complementan.

Palabras claves: muerte, totalidad, existencia, fenomenología.
\end{abstract}

\section{The Analysis of Death according to Bernhard Welte Phenomenological Considerations}

\begin{abstract}
The paper deals with the phenomenological approach to death. The starting point of the reflection is Bernhard Welte's description of death as a moment in which a buman being achieves his wholeness. Thus, when regarding a dead person, we experience a transfiguration in his/her image in such a way that the moment of death can be spoken about as a numinous and sacred instant. Comparing this description with Martin Heidegger's analysis in Being and Time, we see a different approach. Heidegger attempts to show that death cannot be defined by dealing with the death of another person, but only by describing the individual's relationship to his/her own death. Finally the text discusses Eugen Fink's notion of death, which has two aspects: the solitary dimension (one's own death) and its social dimension (the death of others). Both dimensions are complementary.
\end{abstract}

Key words: death, wholeness, existence, phenomenology.

Doctor en Filosofía por la Albert-Ludwigs-Universität Freiburg (Alemania). Académico del Departamento de Filosofía, perteneciente a la Facultad de Ciencias Religiosas y Filosóficas, de la Universidad Católica del Maule. Entre sus publicaciones destacan: Philosophie und Welt beim jungen Heidegger (2002); Mundo y existencia (2006); "Bernhard Weltes produktive Heidegger-Rezeption in Heilsverständnis" y "Der Begriff, Verstehen' bei Bernhard Welte", ambos en la obra colectiva Phänomenologie und Theologie im Gespräch. Impulse von Bernhard Welte und Klaus Hemmerle (2013). 


\section{Introducción}

En su libro Heilsverständnis (Comprensión de salvación) Welte desarrolla una argumentación que apunta a mostrar que la comprensión de ser constituye, a fin de cuentas, una comprensión de salvación. "In diesem Sinne ist Seinsverständnis als solches Heilsverständnis, und dies aus seinem ersten Ursprung» (Welte, 2006a: 80). La noción de comprensión por él utilizada tiene un claro tinte heideggeriano: se trata, en primera instancia, de un proyecto de posibilidades desde el cual, a su vez, se mira — por así decir, en reversa- el propio presente de la existencia humana. Ahora bien, para Welte tal proyecto incluye, como el por-mor-de a que toda acción de la existencia conduce, una idea de la salvación (Idee des Heiles [Welte, 2006a: 105]). «El ser humano se entiende a sí mismo en referencia a su por-morde como a su salvación. Proyecta de antemano en tal comprenderse en referencia a su por-mor-de siempre ya su salvación». Quiere ello decir que el sentido desde el cual el ser humano interpreta su propio presente tiene - para Welte- el carácter de un ser pleno e íntegro, o sea, de lo que, en la lengua alemana, se expresa mediante el adjetivo $\langle h e i l\rangle^{2}$.

Sin embargo, la existencia concreta de cada uno hace patente que dicha idea de salvación como ser pleno choca con la cruda realidad. Pues el ser humano experimenta también el fracaso, la enfermedad, el sinsentido, la muerte, la injusticia. Y un largo etcétera. En otras palabras, el ser humano experimenta una fundamental diferencia entre el sentido del ser como un sentido de plenitud y la concreta vivencia de finitud y limitación. Esta diferencia se articula, según Welte (2006a: 105), de una manera doble: es, por una parte, la diferencia interna de la comprensión de ser; aquí sucede que la existencia humana, como decíamos, se entiende en referencia a su por-mor-de como a su salvación posible. Pero también es verdad que la salvación e integridad a que la vida humana aspira no es solamente posibilidad, sino realidad. Es una salvación real. Estamos en el ámbito de una diferencia que se da al interior de la comprensión de ser; y visto así, el proyecto del por-mor-de puede ser llamado, dice Welte (2006a: 105), «la idea de la salvación»; a su vez, dicha

1 La traducción es mía. El original es el siguiente: «Der Mensch versteht sich auf sein Worum-willen als auf sein Heil. Er entwirft in solchem Sichverstehen auf sein Worum-willen sein Heil immer schon im voraus, [...]» (Welte, 2006a: 103).

2 Sin lugar a dudas, los análisis que Welte propone tienen, finalmente, un sentido teológico. «Desde su punto de partida, los fenómenos, que se muestran desde sí mismos y desde sí mismos se dejan ver, accede Welte en todas sus reflexiones a la posibilidad de dirigir su pensamiento de modo no constrictivo al Dios que se revela en Jesucristo» (Hünermann, 2011: 145). Esta afirmación tiene, por cierto, también validez tocante a la noción de lo sagrado. 
diferencia puede ser determinada como diferencia ideal. Por otra parte, la diferencia también puede acontecer entre la realidad fáctica de la existencia humana, con todos sus vaivenes, y la idea de la salvación arriba esbozada.

Pues bien, a partir de este segundo momento de la articulación se estructura el método fenomenológico que aborda el examen de la diferencia. En lo esencial, se trata de dos partes: primero, se examinan las estructuras generales de la existencia humana en el mundo desde la perspectiva de la pregunta por la salvación; y segundo, se estudian momentos peculiares y relevantes de la existencia (Welte, 2006a: 105), en concreto, los fenómenos de la muerte y de la culpa ${ }^{3}$.

\section{El análisis de la existencia humana según Welte}

Veamos de forma somera lo que se gana con el examen de las relaciones fundamentales de la realidad humana y sus estructuras. Welte habla a este respecto de una dialéctica de lo finito (Welte, 2006a: 107), que hace patente una fundamental ambigüedad de la realidad humana. «En tanto que estamos ahí en nuestro mundo, y, en él y sobre su fundamento, nos relacionamos, por de pronto, con el ente del mundo, nos habla por doquier lo finito y calla por doquier lo infinito. [...] La finitud habla y lo eterno calla» ${ }^{4}$. Pero no se trata aquí de una pura ausencia de lo infinito. En efecto, afirma también Bernhard Welte:

Así pues, el lenguaje del ente del mundo es, para nuestra existencia en el mundo [Weltdasein], por de pronto y siempre ambiguo en el más alto grado. Por una parte, nos habla de sentido, plenitud y salvación, y a la vez nos sustrae de esto. Constantemente le da alas a la esperanza y, a una, la decepciona. Pone a la existencia en un estado de vacilación entre la angustia y la seguridad que nunca se decide totalmente ${ }^{5}$.

\footnotetext{
3 Para un examen de ambas temáticas considérese mi estudio Mundo y existencia: en lo tocante a la culpa, \11; en lo tocante a la muerte, $\$ 12$ (Lambert, 2006: 120-158).

$4 \quad$ La traducción es mía. El original es el siguiente: «Indem wir da sind in unserer Welt spricht überall zu uns das Endliche und schweigt überall das Unendliche. [...] Die Endlichkeit spricht und das Ewige schweigt» (Welte, 2006a: 106).

5 La traducción es mía. El original es el siguiente: «So ist die Sprache des Seienden der Welt für uns in unserem Weltdasein zunächst immer aufs höchste zweideutig. Sie spricht einerseits von Sinn und Erfüllung und Heil und versagt solches zugleich. Sie beflügelt ständig die Hoffnung und enttäuscht sie zugleich. Sie läßt das Dasein in dieser Welt schwanken zwischen Angst und Zuversicht in einer nie ganz zu entscheidenden Schwebe» (Welte, 2006a: 108-109).
} 
Por su parte, a esta ambigüedad constitutiva del ente del mundo le corresponde, en la propia existencia, una vivencia particular, que Welte (2006a: 109) denomina «la ambigua y sospechosa inquietud (die zweidentige und verdächtige Bedenklichkeit)». He aquí la figura primera y más general de la diferencia fáctica de salvación según Welte (2006a: 109). Estamos ante un fenómeno estructural y omniabarcante: el ente del mundo no constituye, si se quiere, un vestigio o peldaño que conduzca desde las realidades sensibles hacia lo infinito. Antes bien, nos movemos en un mundo ambiguo que, a veces, despierta esperanzas, pero muchas veces también las frustra.

Para los efectos de la temática de la muerte es importante reconocer que el primer paso metódico no desemboca en resultados concluyentes. Sí es decisivo que la asimetría entre lo finito y lo infinito repercute también en el segundo paso metódico.

El segundo paso, hemos dicho, tiene que ver con un análisis de momentos peculiares de la existencia humana, concretamente, de la muerte y de la culpa. La elección de estos fenómenos no es casual ni arbitraria. Pues se relaciona con lo que Welte (2006a: 111) llama un doble aspecto de la constitución de la existencia humana. Por una parte, los seres humanos existimos de tal modo que la existencia nos ha sido impuesta. Se trata, entonces, del ser como imposición y destino (Sein als Verhängnis und Geschick [Welte, 2006a: 111]). Por otra parte, el hecho de tener que ser le ha sido confiado al propio ser humano. Se trata, pues, del ser como realización (Sein als Vollzug [Welte, 2006a: 111]). A su vez, debe tomarse en consideración que tales determinaciones corresponden, en lo fundamental, a lo que Heidegger llama proyecto arrojado (geworfener Entwurf [Heidegger, 1993: 199, 223, 285]).

Así pues, la muerte termina con nuestra existencia como imposición; y la culpa, con la existencia como autorrealización. En el presente escrito interesa, ante todo, el análisis de ese momento peculiar que es la muerte, cuya descripción toma su punto de arranque de la experiencia niveladora de la cotidiana huida de la muerte. Pero cuando la existencia humana ya no huye de la muerte, sino que se instala ante la verdad de ésta, entonces la muerte misma hace patente algo: «que [ella] reúne y abarca todo el contenido de ser de la existencia, para entregarlo a su nulidad $»^{6}$. Quiere ello decir que dos son, por así decir, las dimensiones de la muerte que merecen un análisis más atento: la muerte tiene un carácter reuniente de

\footnotetext{
6 La traducción es mía. El original es el siguiente: «In dieser Stellung zeigt er [=der Tod] dann, daß er den ganzen Seinsgehalt des Daseins in sich versammelt und umfängt, um ihn seiner Nichtigkeit preszugeben» (Welte, 2006a: 113).
} 
la existencia humana en total; y la muerte entrega toda la existencia a una desaparición completa que aquí es denominada nulidad (Nichtigkeit).

\section{Los cinco pasos del análisis de la muerte}

Pues bien, el desarrollo del análisis fenomenológico de la muerte en el $\$ 9$ de Heilsverständnis se articula en cinco pasos, que corresponden a los cinco apartados de dicho parágrafo. En términos generales cabe señalar que este análisis es, en buena parte, deudor del enfoque que Heidegger hace en Ser y tiempo, pues de lo que allí se trata es justamente de abordar la pregunta por la totalidad de la existencia desde la estructura del estar vuelto hacia la muerte (Heidegger, 1993: 234).

Por nuestra parte, vamos a dividir los cinco apartados en dos grupos: los dos primeros abordan, ante todo, la propia muerte; los dos siguientes se ocupan, principalmente, de la muerte del otro; y el último apartado constituye una síntesis de ambos momentos. El propio Welte no hace esta división, pero resulta interesante destacarla a propósito del enfoque heideggeriano en Ser y tiempo.

El primer apartado del $\$ 9$ de Comprensión de salvación tematiza la muerte como reunión de la totalidad de la existencia. «La muerte no abarca solo el último instante de la existencia. Abarca la totalidad de la existencia» ${ }^{7}$. Asimismo, ella reúne toda posibilidad y con ello todo futuro de la existencia (Welte, 2006a: 113). La comparación que el autor propone, en lo tocante al carácter reunidor, es harto elocuente: es como el fin de la música. Pues una composición musical está totalmente ahí recién en el momento de su fin, «cuando el último de los sonidos ha pasado» (Trad. mía. Welte, 2006a: 114). A su vez, la muerte le da a la existencia, en todos sus momentos particulares, el carácter de lo único y definitivo. «Por eso, los instantes de nuestra existencia no son arbitrarios ni, en el fondo, repetibles en caso alguno. Las posibilidades que se nos ofrecen son únicas y no se repiten en total y en sentido estricto» ${ }^{8}$.

La traducción es mía. El original es el siguiente: «Der Tod umfaßt nicht etwa nur den letzten Augenblick des Daseins. Er umfaßt das Ganze des Daseins» (Welte, 2006a: 113). Por su parte, en su artículo sobre la muerte en el Diccionario práctico de antropología pastoral insiste Welte en esta dimensión de totalidad: «Ningún acontecimiento es tan totalizador, tan enteramente tomador del hombre como la muerte». Trad. mía. El originarl reza así: «Kein Ereignis ist so total, so den Menschen ganz nehmend wie der T.» [Welte, 2006b: 149).

8 La traducción es mía. El original es el siguiente: «Die Augenblicke unseres Daseins sind von daher nicht beliebig und im Grunde überhaupt nicht wiederholbar. Die 
El segundo apartado aborda la muerte como negatividad. En efecto, la muerte entrega lo reunido como totalidad a la negatividad del no-sermás (Welte, 2006a: 114); consume totalmente lo reunido, dice Welte, y lo arranca. Así, lo propio del acontecimiento del morir es justamente este arrancar, o sea, el puro hecho negativo de que alguien ha dejado de ser por entero: «todo se acabó por completo» (Trad. mía. Welte, 2006a: 115). Ahora bien, este acontecimiento de carácter negativo hace patente lo que el autor llama positividad del ser (Welte, 2006a: 115). «Solo porque el ser humano se entiende en su ser en vistas al ser, en concreto, en vistas al ser-entero salvo [heiles Ganæsein], puede la muerte dársele a entender como negatividad, como contradicción respecto del ser-íntegro [Heilsein] que le atañe en cada caso»?

Es más, la contradicción mencionada permite que el proyecto humano de plenitud e integridad sea sacado a luz desde sus encubrimientos y nivelaciones cotidianas. He ahí también por qué la muerte constituye un dolor. No tanto por los dolores físicos que muchas veces la anteceden, cuanto por la experiencia de la contradicción con la idea esencial del ser humano que con la muerte se termina por completo.

El tercer apartado propone la tesis central de que, en medio del no poder ser salvo ni íntegro que la muerte trae consigo (esto es, la negatividad arriba expuesta), acontece algo así como una seña de una posible salvación trascendente y numinosa (Welte, 2006a: 119) ${ }^{10}$. ¿Cómo llega Welte a esto? Afirma el autor que, cuando la muerte comparece ante alguien, el comportamiento de éste consiste, ante todo, en callar. «Ante la presencia de la muerte pierden su peso las palabras inconsistentes; pierden su peso las habladurías. En el fondo, pierde su peso toda forma de hablar» ${ }^{11}$. Si, entonces, la negatividad de la muerte implica un esencial silencio por parte de ésta, el comportamiento humano correspondiente se estructura como una pérdida de peso de todo hablar. Según Welte, se trata de un callar que procede de un estar conmovido. «Quien calla ante la muerte es alguien cuyo silencio es un

Möglichkeiten, die sich uns anbieten, sind einmalig und wiederholen sich nie mehr im ganzen und eigentlichen Sinn» (Welte, 2006a: 114).

$9 \quad$ La traducción es mía. El original es el siguiente: «Nur weil der Mensch in seinem Sein sich auf Sein, und zwar auf heiles Ganzsein, hin versteht, kann sich ihm der Tod als Negativität, als Widerstreit gegen das Heilsein, um das es je geht, zu verstehen geben» (Welte, 2006a: 115).

10 Respecto de la noción de «numinoso» en Welte, que - sin lugar a dudas- procede de R. Otto, remito a las importantes consideraciones de Kienzler (2004: 298-292).

11 La traducción es mía. El original es el siguiente: «Vor der Präsenz des Todes vergehen die leichten Worte, vergeht das Gerede. Es vergeht davor im Grunde jede Rede» (Welte, 2006a: 116). 
silencio del estar conmovido. En su conmoción se trata de un silencio que está lleno del contenido de la muerte» ${ }^{12}$. Y esta dimensión tiene que ver con la forma como se presenta aquel que ha muerto. Pues, en ocasiones como éstas, lo que despunta tiene el carácter de la majestuosidad, del respeto y de la solemnidad (Welte, 2006a: 116). Quiere ello decir que el muerto se les presenta a los vivos - al menos, a sus más cercanos- con esta «aureola» (la palabra es mía) de solemnidad y majestuosidad.

Pues bien, he aquí que estamos ante un ámbito de trascendencia sagrada. "Allí la muerte le muestra a la existencia - a que ha puesto a tono con el callar del respeto- la cercanía de lo sácrum, de lo sagrado» ${ }^{13}$. Lo que Welte hace en este punto es presentar un dato fenoménico, que de alguna manera a todos nos resulta familiar, pero que él, a su vez, interpreta en términos de sacralidad. En efecto, algo sucede con la persona que ha muerto: no solo, como es obvio, ha dejado de vivir, sino que, a una con ello, comparece algo más: una inviolabilidad de cualidad sagrada (eine Unantastbarkeit von sakraler Qualität [Welte, 2006a: 118]). «El fundamento de esta purificación - que parte del misterio de la muertede la imagen del muerto en dirección a su inviolabilidad se halla en un acrecentamiento que la muerte opera en la imagen del muerto para los vivos» ${ }^{14}$. Parece, entonces, que el acontecimiento del morir no solo destruye toda realidad y posibilidad humanas, sino que, también, se convierte para los vivos en una señal de salvación numinosa.

Por su parte, el cuarto apartado se ocupa de la relación ambigua que se da entre la cara negativa y la cara positiva de la muerte. El aspecto negativo hace referencia a la amenaza, la destrucción y espanto que ella implica. El aspecto positivo tiene que ver con la seña que procede de lo que Welte caracteriza como el «hermoso rayo de elevación y transfiguración que podemos percibir en el rostro del muerto» ${ }^{15}$. Pues bien, el aspecto negativo de la amenaza es inequívoco, o sea que es

12 La traducción es mía. El original es el siguiente: «Wer vor dem Tode verstummt, dessen Schweigen ist ein Schweigen der Betroffenheit. In seiner Betroffenheit ist das Schweigen von dem Gehalt des Todes erfüllt» (Welte, 2006a: 116).

13 La traducción es mía. El original es el siguiente: «Darin aber zeigt der Tod dem Dasein, das er in das Verstummen der Ehrfurcht stimmte, die Nähe des Sacrum, des Heiligen» (Welte, 2006a: 117).

14 La traducción es mía. El original es el siguiente: «Der Grund für diese vom Geheimnis des Todes ausgehende Reinigung des Bildes des Toten ins Unantastbare liegt in einer Steigerung, die der Tod am Bilde des Toten im Angesichte der Lebenden vollbringt» (Welte, 2006a: 118).

15 La traducción es mía. El original es el siguiente: «Der schöne Strahl von Erhöhung und Verklärung, den wir auf dem Antlitz des Toten wahrnehmen können» (Welte, 2006a: 120). 
evidente a todas luces. En cambio, el aspecto positivo de la promesa de salvación numinosa es siempre ambiguo (zweideutig). Pues la transfiguración en la imagen del muerto queda envuelta «en un rechazador carácter desazonador» (in die abweisende Unheimlichkeit [Trad. mía. Welte, 2006a: 120]). El aspecto positivo nunca alcanza, pues, a tener el grado de evidencia e indubitabilidad que tiene el negativo. Más bien, se da un predominio de éste por sobre aquél. He ahí, en definitiva, la desazón que provoca la muerte.

El quinto apartado constituye, como se dijo arriba, una síntesis de los dos grandes momentos en que se articula el análisis de la muerte. Recuérdese que la tesis de Welte es que la comprensión de ser es, en definitiva, comprensión de salvación. A este respecto destaca el autor que los seres humanos no habrán comprendido el sentido de su existencia y eventual salvación si no han comprendido la muerte (Welte, 2006a: 121). En efecto, solo la muerte «capta en sentido eminente la totalidad de la vida humana y le pone un sello de lo único y de totalidad $\gg^{16}$. Comprender la propia muerte trae, pues, consigo comprender el poder-ser-total de la propia existencia y su sentido global. $\mathrm{Si}$, además, este sentido global es, de una forma u otra, plenitud, salvación, entonces quiere decir que la salvación debe abarcar e incluir la muerte. Para Welte resulta absurdo pensar la salvación y la totalidad de sentido de la existencia, pero excluir de esta consideración el fenómeno de la muerte.

Junto con lo anterior, la muerte le da a entender a la existencia algo harto concreto: «que su salvación, la eterna e infinita, no se encuentra en el campo de su poder y de lo que tiene a mano» ${ }^{17}$. Es cierto que el misterio que despunta con el morir abre nuevas posibilidades. Pero estas —según Welte (2006a: 121) - quedan sustraídas al disponer humano. Estamos, pues, en una dimensión en la que, por una parte, el ser humano se puede abrir al misterio con libertad; y, por otra parte, el poder humano encuentra aquí un claro límite. Pues las posibilidades que despuntan con la muerte se sustraen de todo disponer y manejar por parte del hombre.

Un último paso relativo a la síntesis consiste en sostener que la seña de la muerte le da a entender al ser humano que él, si quiere alcanzar plenitud y salvación, tiene que entregarse sin condiciones al misterio

16 La traducción es mía. El original es el siguiente: «Dies geht einfach daraus hervor, daß der Tod, und er allein, das Ganze des menschlichen Lebens in eminentem Sinne erfaßt und in seiner Einmaligkeit und Ganzheit besiegelt» (Welte, 2006a: 121).

17 La traducción es mía. El original es el siguiente: «Dieses [=das Dasein] solle verstehen, daß sein Heil, das ewige und unendliche, nicht im Bereiche seiner Hand und seiner Macht liege» (Welte, 2006a: 121). 
infinito -misterio que, a la vez, resulta oscuro y desazonador-. Pero asimismo esta seña de la muerte destaca que, si bien aquí se da la posibilidad de la esperanza, el hecho inconcuso es que no hay ninguna promesa segura (Welte, 2006a: 121-122). Podría ser que todo terminara en una pura nada absurda.

Así pues, el análisis weltiano de la muerte concluye en lo que antes llamó ambigua y sospechosa inquietud. Pero esta inquietud (Bedenklichkeit) ha alcanzado, en virtud del análisis de la muerte, una agudeza y una diferenciación mayores, sostiene Welte. En efecto: «La diferencia fáctica de salvación de la existencia humana ha adquirido un perfil más nítido, y lo adquiere siempre de nuevo en la mirada hacia la muerte» $^{18}$. He ahí, pues, el resultado de las indagaciones sobre la muerte en Heilsverständnis.

Por nuestra parte, queremos retomar la idea arriba esbozada de que, en los análisis de Welte, hay, por así decir, una doble mirada. Por un lado, tematiza el morir desde la perspectiva del poder-ser-total de la existencia humana y desde el aspecto de la negatividad que implica el morir en tanto que dejar de ser. Aquí lo que se analiza, estrictamente hablando, es la propia muerte. Es $m i$ vida la que alcanza una reunión y síntesis con mi propia muerte -al modo de la composición musical mencionada-. Soy, en cada caso, yo el que va a dejar de ser y se va a acabar por entero. Por otro lado, el callar conmovido que se produce ante la presencia de la muerte; la comparecencia de una cualidad transfiguradora, sagrada, en aquel que ha muerto; y la ambigüedad que aquí se da; todo ello tiene que ver, no con la propia muerte, sino con la de otra persona, de un cercano, y no puede ser experimentada por el propio muerto. Con todo, este paso metódico no es parte de la reflexión explícita por parte de Welte. Mi hipótesis al respecto es que ese paso implica una crítica fundamental a los supuestos de Heidegger en su análisis de la muerte en Ser y tiempo. Pero como Welte señala deberle mucho a la mirada heideggeriana, parece razonable que la crítica (o no aceptación de determinados supuestos) se mantenga en una esfera de lo tácito, de lo implícitamente afirmado.

\footnotetext{
18 La traducción es mía. El original es el siguiente: «Die faktische Heilsdifferenz des menschlichen Daseins hat durchgebildetes Profil bekommen und bekommt es von diesem Hinblick auf den Tod immer wieder neu» (Welte, 2006a: 122).
} 


\section{El acceso fenomenológico a la muerte según Heidegger}

En lo que sigue nos ocuparemos sucintamente del análisis de la muerte que Heidegger ofrece en Ser y tiempo. Ello con el propósito de esclarecer la deuda que Welte dice tener con el planteamiento heideggeriano. En Ser y tiempo la reflexión correspondiente toma su punto de arranque en una dificultad metodológica: la necesidad de sacar a luz el ser de ese ente que, en cada caso, somos nosotros - y que Heidegger fija conceptualmente como Dasein - en su propiedad y totalidad (Heidegger, 1993: 233). Así pues, la tematización fenomenológica de la muerte o, para ser más exactos, del estar vuelto hacia la muerte (das Sein zum Tode) apunta a alcanzar el ser total del Dasein ${ }^{19}$.

Pero la idea de totalidad de la existencia —entendida como el conjunto de sus fases momentáneas- entra en colisión con la estructura fundamental del Dasein, que es el cuidado (Sorge). En efecto, uno de sus momentos constitutivos es el «anticiparse a sí» (Sichvorweg [Heidegger, 1993: 236]) y este momento pone de relieve que la existencia humana tiene siempre algo ante sí, aun en los instantes finales, cuando ya ha «saldado sus cuentas» (Heidegger, 1993: 236). «En efecto, este momento estructural del cuidado dice inequívocamente que en el Dasein siempre hay algo que todavía falta, que, como poder-ser de sí mismo, no se ha hecho aún "real"» (Heidegger, 1997: 257) 20.

Por otra parte, cuando el Dasein ha alcanzado, efectivamente, su totalidad, no puede tener experiencia de ella. Pues su ser se ha aniquilado (Heidegger, 1997: 257-258). «Mientras el Dasein, en cuanto ente, es, jamás habrá alcanzado su 'integridad' [seine «Gänze»]. Pero si la alcanza, este logro se convierte en la absoluta pérdida del estar-en-el-mundo» (Heidegger, 1997: 257-258) ${ }^{21}$. La consecuencia que Heidegger saca de este estado de cosas, y que él anuncia desde el comienzo de su abordaje, en el $\ 45$ de Ser y tiempo, es que la tematización de la muerte desde la perspectiva filosófica del análisis fundamental del Dasein va a consistir en el examen de la relación que tiene la existencia humana con su propio

19 A este respecto Demske habla justamente de un «existencial de totalidad del Dasein»: «Im Anfangsstadium, d.h. in der Daseinsanalyse von Sein und Zeit, ist der Tod das ,Ganzheitsexistenzial' des Daseins: er bestimmt die Ganzheit der menschlichen Existenz und umfaßt sie» (Demske, 1984: 13).

20 El pasaje original es el siguiente: «Dieses Strukturmoment der Sorge sagt doch unzweideutig, daß im Dasein immer noch etwas aussteht, was als Seinkönnen seiner selbst noch nicht ,wirklich' geworden ist» (Heidegger, 1993: 236).

21 El original reza: «Solange das Dasein als Seiendes ist, hat es seine ,Gänze` nie erreicht. Gewinnt es sie aber, dann wird der Gewinn zum Verlust des In-der-Welt-seins schlechthin» (Heidegger, 1993: 236). 
$\mathrm{fin}^{22}$. Quiera o no el ser humano, de una forma u otra, se relaciona con su propia muerte: «[...] si hablamos de un modo que sea conforme al Dasein, la muerte sólo es en un existentivo estar vuelto hacia la muerte» (Heidegger, 1997: 254) ${ }^{23}$. Lo que se va a estudiar, entonces, es el modo de ser de la existencia humana; algo, por tanto, que pertenece a su estructura fundamental, y que no corresponde a un acontecimiento particular dentro de muchos otros. En esta línea Iribarne (2011: 133-134) habla de una refluencia de la finitud de la existencia sobre la vida: la muerte obra constantemente sobre el modo de vivir la vida. Por su parte, Demske (1984: 16) destaca que, en este enfoque, la mirada de la muerte se lleva a cabo «hacia atrás», esto es, desde la muerte en reversa hacia la vida. Así, es precisamente en ese momento estructural de la relación con el propio fin que el análisis filosófico se va a encontrar con la buscada totalidad (Heidegger, 1993: 234).

Una vez fijadas las coordenadas del análisis heideggeriano de la muerte, cuya presentación excede la temática del presente escrito ${ }^{24}$, es preciso estudiar uno de sus corolarios más relevantes, a saber, la imposibilidad de abordar el examen de la muerte a partir de la muerte de los otros (Heidegger, 1993: 237-241). Heidegger habla a este respecto de un Ersatzt thema, o sea, de un tema sucedáneo. Si en virtud de la estructura del cuidado no es posible tener experiencia de la propia totalidad, al menos se podría aprehender esta última en aquellos que ya han llegado a su fin, en los difuntos.

A este respecto Heidegger (1993: 239) afirma que es cierto que, en el caso de los otros, la muerte se devela como pérdida, pero en realidad de lo que se trata es de una pérdida para los que quedan. No es, por tanto, la misma pérdida la de la aniquilación que sufre el muerto y la de los

22 Esta relación de la existencia con su propio fin debe, a su vez, ser entendida como posibilidad. A tal respecto afirma Vattimo lo siguiente: «[...] al anticiparse en la propia muerte, el Dasein ya no está disperso ni fragmentado en las diferentes posibilidades rígidas y aisladas, sino que las asume como posibilidades propias que incluye en un proceso de desarrollo siempre abierto precisamente por ser siempre un proceso para la muerte. La muerte posibilita las posibilidades, las hace aparecer verdaderamente como tales y así las pone en posesión del Dasein, que no se aferra a ninguna de ellas de manera definitiva, sino que las inserta en el contexto siempre abierto del proyecto propio de la existencia. A partir de ahora podemos afirmar que sólo al anticipar la muerte propia, que posibilita posibilidades, el Dasein tiene una historia, es decir, un desenvolvimiento unitario más allá de la fragmentación y de la dispersión» (Vattimo, 2002: 50).

23 El original es el siguiente: «Daseinsmäßig aber ist der Tod nur in einem existenziellen Sein zum Tode» (Heidegger, 1993: 234).

24 Dicho análisis desemboca en la idea de un adelantarse hasta la muerte (Vorlaufen in den Tod [Heidegger, 1993: 263]) y de libertad para la muerte (Freibeit zum Tode [Heidegger, 1993: 266]). 
deudos a quienes alguien les ha sido arrebatado. Entonces, lo que aquí sucede es que, según Heidegger (1993: 239), en el padecer específico de la pérdida que implica la muerte de los otros no resulta accesible la pérdida de ser como tal. «No experimentamos, en sentido propio, el morir de los otros, sino que, a lo sumo, solamente 'asistimos' a él» (Heidegger, 1997: $260)^{25}$.

Por otra parte, debe considerarse también lo que Heidegger llama reemplazabilidad (Vertretbarkeit). Si se ha reconocido que es imposible tener experiencia de la totalidad de la existencia en la propia muerte, hay, según Heidegger, un planteamiento que sostiene que, para el análisis de la totalidad de la existencia, se puede tomar como tema sucedáneo la muerte de los otros. Así, lo que no resulta experimentable en la propia existencia, sería accesible en la existencia del prójimo. Ahora bien, este planteamiento arranca, según Heidegger, del supuesto que, en toda circunstancia, un ser humano puede ser reemplazado por otro (Heidegger, 1993: 239). Pero tal posibilidad de reemplazar, que tiene un amplio espectro en la vida cotidiana, fracasa en el caso de la muerte. En efecto: «Nadie puede tomarle al otro su morir» (Heidegger, 1997: 261) ${ }^{26}$. El morir es, en cada caso, mío. No cabe, pues, aquí ninguna posibilidad de reemplazo ${ }^{27}$; y esta afirmación tiene validez en dos planos diversos: en el morir mismo como acontecimiento y en el análisis fenomenológico, que, por así decir, se pliega a la estructura de la realidad.

Pues bien, el resultado de estas consideraciones heideggerianas es que, bajo ningún respecto, cabe realizar un análisis de la muerte por la vía sucedánea del morir de los otros. Pues ello implica, en definitiva, un desconocimiento, según el autor, del modo de ser del Dasein.

\section{Evaluación de la propuesta de Welte}

Consideremos, a la luz de lo visto, el análisis que Welte ofrece de la muerte. Éste se enmarca, en buena medida, en el esquema que Heidegger

\footnotetext{
25 Dice el original: «Wir erfahren nicht im genuinen Sinne das Sterben der Anderen, sondern sind höchstens immer ,dabei'» (Heidegger, 1993: 239).

26 El original reza: «Keiner kann dem Anderen sein Sterben abnehmen» (Heidegger, 1993: 240).

27 Tocante a este punto la crítica de Hügli \& Han (2001: 137-138) es acertada. Afirman que el morir no constituye la única posibilidad de la co-existencia que resulta irreemplazable. Si bien es cierto, dicen los autores, otra persona puede ir en vez de mí a una librería a comprar un libro, nadie me puede reemplazar cuando voy al médico para ser tratado por él. «Es gibt im Grunde wenig Seinsmöglichkeiten, bei denen ich wirklich vertretbar wäre» (2001: 138).
} 
ofrece en Sery tiempo: el ser humano es proyecto arrojado, que, en cuanto proyecto, esboza con libertad un futuro desde el cual «lee» hacia atrás su presente. Ese futuro, una vez que se concreta de forma definitiva, corresponde al ser total de la existencia; y esta totalidad se alcanza justamente con la propia muerte. Por eso, el examen fenomenológico de la muerte debe enfocar ésta desde el mencionado momento de totalidad.

A su vez, Welte intenta mostrar en la experiencia de la muerte un instante numinoso de carácter sacro. Este carácter tiene que ver con una suerte de purificación y acrecentamiento en la imagen del difunto para los vivos. Ahora bien, lo decisivo del aporte de Welte se conquista por medio de un análisis de la muerte de los otros. Sin embargo, hemos visto que, desde los supuestos heideggerianos en Ser y tiempo, este tipo de enfoque implica para el autor - como hemos visto- nada menos que un desconocimiento del modo de ser de la existencia humana.

Así vistas las cosas, para nosotros, los intérpretes de los textos, caben —dicho esquemáticamente- dos posibilidades: o bien Welte no percibió la transgresión de los supuestos heideggerianos; o bien, no estando en el fondo de acuerdo con ellos, veladamente los critica, y, por así decir, amplía el enfoque del examen de la muerte. Nuestro modelo interpretativo opta por la segunda de las alternativas, ante todo, porque ofrece mayores posibilidades para la reflexión filosófica.

\section{El acceso fenomenológico a la muerte según Fink}

El hecho que, desde una perspectiva fenomenológica, sea razonable un abordaje de la muerte que incluya como parte esencial la experiencia de la muerte de los otros, lo atestigua —entre otros- Eugen Fink en la lección Grundphänomene des menschlichen Daseins (1995) ${ }^{28}$. Iribarne (2011: 141) destaca, a propósito de este texto, que en los fenómenos fundamentales a que Fink alude - entre ellos, la muerte- se hace manifiesta precisamente la finitud. La muerte hace, pues, patente que el hombre es finito.

En clara oposición a la visión de Heidegger, para quien no tenemos, en sentido genuino, experiencia del morir de los otros (Heidegger, 1993: 239), para Fink en la comprensión de la muerte ajena está incluida una cierta comprensión, por pobre que sea, de la propia muerte (Fink, 1995: 144). A su vez, en la comprensión de la propia muerte se da también un

28 Se trata de una lección universitaria que Fink dio, con el mismo nombre, en Friburgo el semestre de verano de 1955, según nos informan en el epílogo los editores (Fink, 1995: 454). 
momento de comprensión de ésta como muerte para los demás (Fink, 1995: 144). Veamos, respecto de este segundo momento, lo que dice el autor:

Pero también el moribundo intenta en un cierto grado ver su propio morir con la mirada del prójimo, de los que le sobreviven: toma decisiones sobre su «funeral»; da a conocer un último deseo; dicta disposiciones testamentarias; exhorta a sus hijos, etc. De nuevo salta, planificando voluntariamente, hacia su futuro «después de él», comprende su situación desde el horizonte temporal objetivo del futuro intersubjetivo, aun cuando él mismo ya no va a ser parte de aquel futuro ${ }^{29}$.

Por su parte, la argumentación de Fink en lo tocante al primer momento - la comprensión de la propia muerte en la muerte de los otros- se basa en la certeza «a priori» de la muerte. No llegamos, dice él, a la conclusión que la muerte es inevitable por el hecho que hayamos sido testigos de una serie de casos (Fink, 1995: 144). «El saber que la muerte es algo para nosotros seguro no se alimenta de experiencias de la muerte ajena» ${ }^{30}$. Más bien, la muerte de los otros nos recuerda que vamos a morir (memento morr), y justo por eso la esquivamos. Así pues, tal evasión de la muerte muestra de forma patente, según Fink, «cómo ocultamente en toda comprensión de la muerte ajena se ha ya coentendido la propia muerte» ${ }^{31}$.

Vistas así las cosas, es preciso hablar, según Fink, del aspecto doble de la muerte (der Doppelaspekt des Todes [Fink, 1995: 155]). Uno es su aspecto social: la muerte de los demás; y otro es su aspecto solitario: la propia muerte (Fink, 1995: 146; 155). Fink rechaza a este respecto plantear la pregunta excluyente acerca de cuál de ellos es el más originario. Pues allí operan, según él, prejuicios (Vorentscheidungen) que no son inocuos (Fink, 1995: 146). Con todo, a propósito de este doble aspecto se puede sacar a luz una estructura, a saber, que la muerte del prójimo es «fenómeno», no

29 La traducción es mía. El original es el siguiente: «Aber der Sterbende versucht in einem gewissen Grade, sein eigenes Sterben mit den Augen der Mitmenschen, der Überlebenden zu sehen; er trifft Bestimmungen über sein ,Begräbnis', äußert einen letzten Willen, erläßt testamentarische Verfügungen, ermahnt seine Kinder, usw., er greift nochmal willenmäßig planend in eine Zukunft, nach ihm' aus, versteht seine Situation aus dem objektiven Zeithorizont der intersubjektiven Zukunft, auch wenn er selber an jener Zukunft keinen Anteil mehr haben wird» (Fink, 1995: 144). Texto paralelo: Fink, 1969: 35-36.

30 La traducción es mía. El original es el siguiente: «Das Wissen darum, daß uns der Tod gewiß ist, speist sich nicht aus Erfahrungen von fremdem Tod» (Fink, 1995: 144).

31 La traducción es mía. El original es el siguiente: «wie verdeckterweise in jedem Verstehen fremden Todes der eigene Tod schon mitverstanden ist» (Fink, 1995: 145). 
así la propia. He ahí una estructura que se da y se mantiene siempre, con independencia de las interpretaciones que se hagan de la muerte (Fink, 1995: 147; 1969: 36, 55, 56).

Fink, sin mencionarlo expresamente, critica la concepción heideggeriana que hemos presentado arriba. Hace dos afirmaciones centrales: Primero, que es un error pensar que la relación cotidiana e irreflexiva con la muerte se oriente, ante todo, por la muerte ajena y pase por alto la propia muerte. Segundo, también es un error afirmar que la relación auténtica de la existencia humana con la muerte se alcanza exclusivamente a partir de la relación con la propia muerte (Fink, 1995: 147). Fundamenta ambos asertos en el hecho que se dan interpretaciones cotidianas - o sea, si se quiere, superficiales - de la muerte en cada caso mía; asimismo en que hay interpretaciones profundas de la muerte como fenómeno social. Por otra parte, argumenta el autor, no se debe identificar con cierto apresuramiento la consideración cotidiana e irreflexiva sobre la muerte con una interpretación tradicional de la misma, ni tampoco debe considerarse que en toda interpretación que se presenta como novedosa hay ya «originalidad» (Fink, 1995: 147-148).

Fink, estimamos nosotros, apunta a un análisis de la muerte que se haga con rigor fenomenológico; que cumpla con el principio expresado ya por Husserl en las Investigaciones lógicas: «No pueden satisfacernos significaciones que toman vida - cuando la toman- de intuiciones remotas, confusas, impropias. Queremos retroceder a las 'cosas mismas'» (Husserl, 2001: 128) ${ }^{32}$. Así pues, todo indica que los errores esbozados por Fink corresponden a significaciones que han sido tomadas de intuiciones remotas y confusas.

Veamos de qué forma comparece, según Fink, la muerte cuando es «fenómeno». Afirma que el llegar a su fin de un ser humano es de otra esencia que el llegar a su fin de una piedra, de una planta o de un animal. En efecto, la piedra se deshace (zerfällt), la vida vegetal y animal se extingue (erlischt), y en el caso del ser humano sucede que él se sustrae (entrieht sich) de la comunidad de los vivos (Fink, 1995: 139). «Esta «sustracción» [Entrug] es el problema difícil y oscuro»" ${ }^{33}$. Fink remite en este punto a una consideración usual que, con cierta premura, elude la dificultad. Esto acaece cuando se piensa la sustracción mediante el esquema corriente de un movimiento de lugar, por ejemplo, como

32 El original es el siguiente: «Bedeutungen, die nur von entfernten, verschwommenen, uneigentlichen Anschauungen - wenn überhaupt von irgendwelchen - belebt sind, können uns nicht genug tun. Wir wollen auf die ,Sachen selbst' zurückgehen» (Husserl, 1993: 6).

33 La traducción es mía. El original es el siguiente: «Dieser ,Entzug’ ist das schwierige und dunkle Problem» (Fink, 1995: 139). 
tránsito desde el reino de lo visible hacia un reino invisible de los espíritus (Fink, 1995: 139-140).

Por su parte, la propuesta del autor quiere pensar la sustracción lo más radicalmente posible: como un «sustraerse de la esfera total de la 'presencia' como tal» ${ }^{34}$. Se trata aquí, según Fink, de una separación (Abscheiden); en el caso del difunto estamos ante «el que se ha separado» (der «Abgeschiedene» [Fink, 1995: 140]). Asimismo, en Metaphysik und Tod Fink señala que la sustracción ha de ser entendida como la desaparición (Wegschwinden) desde la presencia, una y omniabarcante, en donde por principio están reunidos «todos los fenómenos» (Fink, 1969: 56). Y a este respecto se dan dos momentos complementarios. Por un lado, sucede que entre los vivos y los que se han separado impera la mayor de las escisiones (herrscht die größte Trennung [Fink, 1995: 140]). Pues desde la sepultura no hay ningún camino hacia atrás y la separación es irrevocable. Por otro lado, pasa igualmente que los muertos incumben a los vivos; llenan —dice Fink- la existencia de los vivos. Pues los vivos no solo se relacionan, en cada caso, consigo mismo y con los demás, sino también con los que han partido, con los ancestros, con los antepasados que hace mucho vivieron, tuvieron su tiempo y ahora descansan en el suelo (Fink, 1995: 140). En síntesis, la sustracción tiene esos dos momentos constitutivos de escisión e incumbencia.

No es éste el lugar para presentar la doctrina completa de Eugen Fink sobre la muerte. Solo hemos esbozado los rasgos del análisis en lo tocante a la primacía de la propia muerte o de la muerte del prójimo. No hemos presentado, por cierto, la tesis central del autor que apunta al hecho que la muerte supone siempre la vida y su carácter fructífero (Fink, 1995: 151ss). Pero nos interesa poner de relieve lo que hemos sacado en limpio de las ideas de Fink para esclarecer el punto de arranque de este escrito: la concepción de la muerte como posible lugar de una promesa de salvación numinosa según Bernhard Welte.

\section{Consideraciones finales}

- Desde el punto de vista fenomenológico no es evidente que el análisis del morir deba orientarse por la muerte propia. Caben distintas miradas que, más que excluirse mutuamente, parece que más bien se complementan. 34 La traducción es mía. El original es el siguiente: «Entzug aus der totalen Sphäre
des ,Anwesens' überhaupt» (Fink, 1995: 140). 
-La muerte es fenómeno, es decir, algo que se muestra, estrictamente hablando, en el caso de la muerte de los otros. Pero es la presencia de una sustracción (Entzug) y de una ausencia.

- Si en el proyecto filosófico de Bernhard Welte la comprensión de ser es comprensión de salvación, y, por su parte, la noción de salvación (beil) tiene que ver con totalidad e integridad, debiera mostrarse con mayor minucia de qué forma la totalidad de la existencia se presenta asociada al elevamiento de la imagen del muerto para los vivos.

-Finalmente: puesto que los análisis de Welte y de Fink son en muchos puntos coincidentes; puesto que ellos, en sentido lato, son parte de una «escuela fenomenológica de Friburgo»; además de ser coetáneos, parece muy razonable profundizar en los paralelos y divergencias de ambos autores. Este escrito quiere ser un aporte en esta dirección.

\section{REFERENCIAS}

-Demske, J. M. (1984). Sein, Mensch und Tod. Das Todesproblem bei Martin Heidegger. Freiburg/München: Alber.

-Fink, E. (1969). Metaphysike und Tod. Stuttgart/Berlin/Köln/Mainz: Kohlhammer.

-Fink, E. (1995). Grundphänomene des menschlichen Daseins, editado por Egon Schütz y Franz-Anton Schwarz, Freiburg/München: Alber.

-Heidegger, M. (1993). Sein und Zeit. Tübingen: Niemeyer.

-Heidegger, M. (1997). Ser y tiempo. (J. E. Rivera, Trad.). Santiago: Editorial Universitaria.

-Hügli, A. \& Han, B.-C. (2001). Heideggers Todesanalyse (\$S 45-53). En Th. Rentsch (Ed.), Martin Heidegger. Sein und Zeit (págs. 133-148). Berlin: Akademie Verlag.

-Hünermann, P. (2011). Bernhard Welte como teólogo fundamental. La significación de la obra filosófica de Bernhard Welte para la teología. Erasmus. Revista para el diálogo intercultural, XIII (2), 135-151.

-Husserl, E. (1993). Logische Untersucbungen. Zweiter Band, I. Teil, Tübingen: Niemeyer.

-Husserl, E. (2001). Investigaciones lógicas (T. I, M. García Morente y J. Gaos, Trads.) Madrid: Alianza.

-Iribarne, J. V. (2011). En torno al sentido de la vida. Ensayos fenomenológicos sobre la existencia. Morelia: Red Utopía A.C./Jitanjáfora/Morelia Editorial.

-Kienzler, K. (2004). Das Heilige im Denken Bernhard Weltes. En M. Enders \& H. Zaborowski (Eds.), Phänomenologie der Religion. Zugänge und Grundfragen, (págs. 287-297). Freiburg/München: Alber.

-Lambert, C. (2006). Mundo y existencia. Consideraciones fenomenológicas desde la perspectiva de Heidegger y Welte. Santiago: Bricklediciones.

-Vattimo, G. (2002). Introducción a Heidegger. Barcelona: Gedisa. 
-Welte, B. (2006a). Heilsverständnis. Philosophische Untersuchungen einiger Voraussetzungen zum Verständnis des Christentums, en: Hermeneutik des Christlichen, Bernhard Welte Gesammelte Schriften, Band IV/1, Freiburg/Basel/Wien: Herder.

-Welte, B. (2006b). Tod (Lexikonsartikel). En Leiblichkeit, Endlichkeit und Unendlichkeit, Bernhard Welte Gesammelte Schriften, Band I/3, Freiburg/Basel/ Wien: Herder.

Sumario: Introducción; 1. El análisis de la existencia humana según Welte; 2. Los cinco pasos del análisis de la muerte; 3 . El acceso fenomenológico a la muerte según Heidegger; 4. Evaluación de la propuesta de Welte; 5. El acceso fenomenológico a la muerte según Fink; 6. Consideraciones finales; Referencias. 